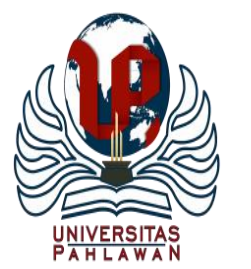

Edukatif : Jurnal Ilmu Pendidikan Volume 3 Nomor 2 Tahun 2021 Halm 404 - 411 EDUKATIF: JURNAL ILMU PENDIDIKAN

Research \& Learning in Education

https://edukatif.org/index.php/edukatif/index

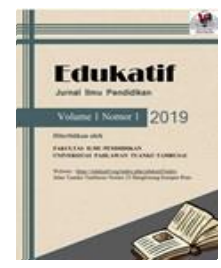

\title{
Validitas Instrument Penerapan Model Quantum Teaching Tipe Tandur terhadap Keterampilan Komunikasi dan Kolaborasi Mahasiswa
}

\author{
Dini Maielfi \\ STKIP Adzkia \\ E-mail : dini.m@stkipadzkia.ac.id
}

\begin{abstract}
Abstrak
Berdasarkan hasil pengamatan ditemukan beberapa pendidik hanya menggunakan instrumen tanpa adanya analisis terhadap validitas dari instrument yang digunakan, sehingga instrument tersebut tidak dapat dipakai untuk melakukan pengukuran terhadap apa yang dihendaki untuk diukur. Tujuan dari riset ini yaitu mendeskripsikan validitas instrument yang digunakan pada penerapan model quantum teaching tipe tandur terhadap keterampilan komunikasi dan kolaborasi mahasiswa STKIP Adzkia. Validitas isi dari instrumen dilakukan dengan memberikan draf validasi kepada para pakar dan praktisi untuk dilakukan penilaian. Jenis penelitian ini memakai metode penelitian deskriptif dengan pendekatan kuantitatif. Analisis yang dipakai pada riset ini yaitu uji validitas isi dari instrumen yang digunakan Hasil penelitian menunjukkan bahwa hasil validasi SAP memperoleh nilai 3,67 dengan kategori sangat valid, hasil validasi modul memperoleh nilai 3,69 dengan kategori sangat valid, serta hasil validasi instrumen penilaian memperoleh nilai 3,67 dengan kategori sangat valid. Implikasi dari penelitian ini yaitu didapatkan instrumen yang layak atau valid sehingga dapat digunakan dalam proses pembelajaran dan dapat dipakai untuk mengukur apa yang hendak diukur. Dan disimpulkan bahwa hasil validitas instrumen yang digunakan pada penerapan model quantum teaching tipe tandur memperoleh kategori sangat valid.
\end{abstract}

Kata Kunci: Validitas, keterampilan komunikasi, keterampilan kolaborasi.

\begin{abstract}
Based on the observations, it was found that some educators only used the instrument without any analysis of the validity of the instrument used, so that the instrument cannot be used to measure what was desired to be measured. The purpose of this research is to describe the validity of the instruments used in the application of the tandur type of quantum teaching model to the communication and collaboration skills of STKIP Adzkia students. The validity of the contents of the instrument was carried out by providing a validation draft to experts and practitioners for assessment. This research used descriptive research methods with a quantitative approach. The analysis used in this research is the content validity test of the instrument used. The results show that the results of the SAP validation got a value of 3.67 with a very valid category, the results of module validation got a value of 3.69 with a very valid category, and the results of the validation of the assessment instrument obtained value of 3.67 with very valid category. The implication of this research is that a proper or valid instrument is obtained so that it can be used in the learning process and to measure what is being measured. And it was concluded that the results of the validity of the instruments used in the application of the tandur type quantum teaching model obtained a very valid category.
\end{abstract}

Keywords: Validity, communication skills, collaboration skills.

Copyright (c) 2021 Dini Maielfi

$\triangle$ Corresponding author

Email : dini.m@stkipadzkia.ac.id

DOI : https://doi.org/10.31004/edukatif.v3i2.316

ISSN 2656-8063 (Media Cetak)

ISSN 2656-8071 (Media Online)

Edukatif : Jurnal Ilmu Pendidikan Vol 3 No 2 Tahun 2021 p-ISSN 2656-8063 e-ISSN 2656-8071 
405 Validitas Instrument Penerapan Model Quantum Teaching Tipe Tandur terhadap Keterampilan Komunikasi dan Kolaborasi Mahasiswa - Dini Maielfi

DOI: https://doi.org/10.31004/edukatif.v3i2.316

\section{PENDAHULUAN}

Penentuan kesuksesan proses belajar mengajar diperlukan agar dapat diketahui level tercapainya tujuan belajar mengajar, maka dibutuhkan instrumen yang bias menggambarkan kesuksesan belajar mengajar dan kepahaman terhadap pokok bahasan yang disampaikan. Untuk itu dibutuhkan intrumen agar mendapatkan informasi mengenai hal tersebut, dengan adanya instrumen belum tentu bisa menjamin representasi tercapainya belajar mengajarjika instrumen yang digunakan tidak bisa dihandalkan. Oleh karena itulah validitas merupakan hal yang dibutuhkan dan menjadi syarat bagi pembuat instrument. Sebelum instrument tersebut digunakan hendaknya dapat dilakukan pengujian kelayakan dari instrument yang akan digunakan. Instrumen adalah alat yang dipergunakan untuk melakukan pengukuran terhadap suatu objek agar diperoleh data (Yusup, 2018). Perancangan instrumen penilaian hendaknya memenuhi kategori agar layak dipakai. Salah satu pengujian yang bisa dipakai yaitu dengan melakukan pengujian validitas. Berdasarkan hasil pengamatan dilapangan ditemukan beberapa pendidik hanya menggunakan instrument tanpa adanya analisis terhadap kelayakan atau validitas dari instrument yang digunakan, sehingga menyebabkan instrument tersebut tidak dapat dipakai untuk melakukan pengukuran terhadap apa yang dihendaki untuk diukur. Hal ini tentunya berbeda dengan yang diharapkan, harusnya instrumen penilaian yang digunakan haruslah berkualitas dan memenuhi kategori valid. Hal ini sesuai dengan yang diungkapkan (Khafidin, 2014) validits tes adalah seberapa mampu tes itu bisa dipakai untuk mengukur segala sesuatu yang hendak diukur. Jadi validitas tes merujuk pada fungsi dari pengukuran tes.

Berdasarkan kajian masalah maka pengujian validitas atau kelayakan instrument sangat dibutuhkan. Pada penelitian ini saya meneliti Validitas isi dari instrumen yang dilakukan dengan memberikan draf validasi kepada para pakar dan praktisi untuk dilakukan penilaian. Instrumen yang saya validasi yaitu terdiri dari SAP, Modul pembelajaran, dan lembar penilaian keterampilan komunikasi dan kolaborasi. Penelitian ini memiliki tujuan penelitian yaitu mendeskripsikan validitas instrument yang digunakan pada penerapan model quantum teaching tipe tandur terhadap keterampilan komunikasi dan kolaborasi mahasiswa STKIP Adzkia.

Penjabaran silabus perkuliahan menjadi Satuan Acara perkuliahan (SAP) perlu dilaksanakan agar pengimplementasian kurikulum dapat berjalan dengan baik. (Ida \& Unsiah, 2018) mengemukakan pada dasarnya, semua dosen harus mempunyai SAP untuk dijadikan rancangan perkuliahan di satu semester yang akan direpresentasikan kepada mahasiswa. Seorang dosen tidak akan sanggup menyampaikan perkuliahan dengan bagus jika dosen itu tidak mempunyai rancangan perkuliahan dan tidak mengetahui tujuan perkuliahan yang ditargetkan. Sehingga, mahasiswa tidak dapat meraih prestasi belajar yang ditargetkan.

Proses belajar mengajar dapat berjalan dengan efektif dan bisa juga dilaksanakan dengan mandiri melalui penggunaan modul dalam pembelajaran. Karena kegunaan modul adalah sebagai bahan dalam belajar yang dipergunakan pada aktivitas pembelajaran mahasiswa. Dengan penggunaan modul mahasiswa bisa belajar dengan terarah dan sistematis. Mahasiswa hendaknya bisa memperoleh kompetesi yang dikehendaki pada aktivitas pembelajaran yang dilaksanakannya. (Mustika \& Sophia, 2019).

Keterampilan komunikasi dan kolaborasi sangat penting dalam pembelajaran dan diharapkan kedua keterampilan ini dapat saling menunjang dalam proses pembelajaran. Menurut Noviyanti Keterampilan komunikasi sangat bermanfaat dalam dunia pendidikan, dan dapat membangun pengetahuan terhadap konsep pembelajaran. Keterampilan ini digunakan agar siswa mempunyai kemampuan mengungkapkan pertanyaan, mengungkapkan ide, melakukan diskusi, berteman, dan mengerti tentang bermasyarakat.(Maielfi \& Wahyuni, 2020). Sedangkan Keterampilan kolaborasi menurut Le, Janssen \& Wubbels adalah kemampuan untuk ikut terlibat pada setiap aktivitas dalam menjalin hubungan dengan orang lain, saling menghormati hubungan dan teamwork agar meraih goal yang sama (Rahmawati, 2019). Mahasiswa hendaknya menumbuhkan keterampilan komunikasi dengan efektif supaya bisa mengemukakan mengenai apa yang dipahaminya pada 
406 Validitas Instrument Penerapan Model Quantum Teaching Tipe Tandur terhadap Keterampilan Komunikasi dan Kolaborasi Mahasiswa - Dini Maielfi

DOI: https://doi.org/10.31004/edukatif.v3i2.316

mahasiswa lain, dan jika mahasiswa mengalami kesusahan dalam memahami materi atau dalam penyelesaian masalah hendaknya dapat melakukan kolaborasi. Oleh sebab itu, aktivitas keterampilan komunikasi dan kolaborasi hendaknya diintegrasikan pada saat proses pembelajaran. (Saenab et al., 2017).

Keterampilan komunikasi dan kolaborasi hendaknya dapat ditumbuhkan dalam proses pembelajaran, oleh sebab itu dalam penelitian ini digunakan model quantum teaching tipe tandur. Quantum Teaching adalah pewujudan berbagai jenis hubungan korelasi yang terdapat di dalam dan di seputar kegiatan belajar. Hubungan korelasi ini terdiri dari komponen agar belajar dapat berhasil dan dapat membuat siswa menjadi sukses. Hubungan korelasi dapat menjadikan kompetensi serta kemampuan alamiah peserta didik menjadi cemerlang dan berguna untuk diri pribadi serta orang lain. Bobby DePorter, mengemukakan strategi belajar mengajar Quantum Teaching dengan istilah TANDUR, yaitu Tumbuhkan, Alami, Namai, Demonstrasikan, Ulangi dan Rayakan. (Khairani \& Ismah, 2016)

Beberapa riset yang terdahulu yang terkait dengan penelitian ini yaitu : 1) Validitas setelah penilaian uji validator pada Modul Multimedia interaktif berbasis Macromedia Director MX memperoleh nilai 90.35,00\%, sehingga kategori validitas dapat dikategorikan sangat valid dan dapat digunakan pada saat pembelajaran (Sepriana et al., 2019) 2) Penelitian yang dikerjakan oleh (Hayati \& Lailatussaadah, 2016) riset ini menggunakan Model Rasch, dan diperoleh nilai validitas yang tidak bertentangan antara item dan konstruk yang dinilai walaupun terdapat hal-hal yang butuh pengkajian. Oleh sebab itu, tes penelitian yang menilai pengetahuan strategi PAKEM guru dinilai tepat dan bisa dipergunakan. 3) berdasarkan uji analisis yang sudah dilaksanaan hingga disimpulkan bahwa secara umum, semua soal PTS mata pelajaran Matematika Wajib kelas XI di MA NU TBS Kudus telah sesuai dengan KD yang ada pada kurikulum 2013 yang berarti bahwa validitas isi dari paket soal PTS mata pelajaran Matematika Wajib kelas XI di MA NU TBS Kudus tahun pelajaran 2018/2019 sudah terpenuhi. (Utomo, 2018).

Berdasarkan penelitian sebelumnya perbedaan penelitian ini dengan penelitian sebelumnya yaitu instrumen penilaian yang dirancang berbeda dengan instrumen pada beberapa penelitian sebelumnya yang relevan. Hal ini dikarenakan pada penelitian sebelumnya yang relevan tersebut belum ada yang mengembangkan dan menguji validitas instrumen penilaian terkait keterampilan komunikasi dan kolaborasi mahasiswa. Maka keterbaruan penelitian ini terletak pada intrumen yang dirancang yaitu intrumen keterampilan komunikasi dan kolaborasi mahasiswa. Pentingnya penelitian ini dilakukan yaitu untuk menghasilkan instrumen yang dipakai saat pembelajaran yaitu terdiri dari SAP, Modul pembelajaran, dan lembar penilaian keterampilan komunikasi dan kolaborasi. Instrumen penilaian ini dirancang berupa lembar observasi dengan beberapa indicator agar memudahkan dalam penilaian dan terhindar dari unsur subjektivitas saat menilai. Selain itu, instrumen penilaian ini dirancang berdasarkan hasil observasi terhadap kebutuhan di lapangan, sehingga dapat dijadikan solusi untuk mengatasi masalah terkait kualitas penilaian instrumen pembelajaran yang layak dipergunakan dalam menilai keterampilan komunikasi dan kolaborasi mahasiswa. Fungsi instrumen penilaian ini yaitu untuk mengukur aspek keterampilan komunikasi dan kolaborasi mahasiswa sehingga dapat mengetahui tingkat keberhasilan mahasiswa dalam pembelajaran.

\section{METODE PENELITIAN}

Jenis riset yang dipergunakan pada riset ini yaitu riset deskriptif dengan pendekatan kuantitatif dengan tujuan menyampaikan sesuatu sesuai dengan keadaannya. Menurut Arikunto penelitian deskriptif bukan ditujukan untuk melakukan pengujian terhadap hipotesis tertentu, tetapi hanya menyampaikan apa adanya mengenai variable tertentu. Melalui penelitian kuantitatif, umumnya diminta untuk memakai angka, berawal dari proses mengumpulkan data, penterjemahan terhadap data, serta penyampaian dari hasil data. (Putra, 2015) Sehingga diambil kesimpulan bahwa penelitian deskriptif kuantitatif pada penelitian ini yaitu untuk 
407 Validitas Instrument Penerapan Model Quantum Teaching Tipe Tandur terhadap Keterampilan Komunikasi dan Kolaborasi Mahasiswa - Dini Maielfi

DOI: https://doi.org/10.31004/edukatif.v3i2.316

melihat, dan menjabarkan dengan angka mengenai subjek yang diteliti apa adanya sesuai dengan hasil kemudian mengambil kesimpulan mengenai hal tersebut berdasarkan hasil yang ditemui ketika penelitian dilaksanakan. Objek penelitian yaitu beberapa instrument berupa lembar observasi atau penilaian terhadap keterampilan komunikasi dan kolaborasi yang dirancang oleh peneliti.

Jenis data pada riset ini adalah data kuantitatif. Data utama pada riset ini yaitu data hasil validasi terhadap instrument yang digunakan pada penerapan model quantum teaching tipe tandur terhadap keterampilan komunikasi dan kolaborasi mahasiswa STKIP Adzkia. Instrumen yang dipakai yaitu berupa lembar validasi terdiri dari lembar validasi SAP, lembar validasi modul, dan lembar validasi penilaian keterampilan komunikasi dan kolaborasi. Data yang diperoleh dari riset ini yaitu skor berdasarkan hasil penilaian pada lembar validasi instrument penelitian yaitu lembar validasi SAP, modul dan lembar penilaian keterampilan komunikasi dan kolaborasi, analisis data dilakukan sebagai berikut : (a). Validator menilai atau memvalidasi instrument penelitian yaitu lembar validasi SAP, modul dan lembar penilaian keterampilan komunikasi dan kolaborasi, (b). Menjumlahkan skor yang diperoleh dari hasil validasi oleh validator, (c). Menganalisis rerata nilai hasil validasi dengan menggunakan rumus yaitu :

$$
\mathbf{R}=\frac{\sum_{\mathrm{j}=1}^{\mathrm{u}} \mathrm{Vij}}{\mathbf{n m}}
$$

Dengan:

$$
\begin{array}{ll}
\mathrm{R} & =\text { rata-rata hasil penilaian dari para pakar } \\
\mathrm{Vij} & =\text { skor hasil penilaian para pakar ke-j kriteria } \mathrm{i} \\
\mathrm{n} & =\text { banyaknya para pakar yang menilai } \\
\mathrm{m} & =\text { banyaknya criteria }
\end{array}
$$

Menurut Widjajanti langkah penentuan tingkatan validitas diperoleh melalui kategori seperti Tabel 1 berikut.

Tabel 1.Kriteria Penetapan Tingkat Kevalidan

\begin{tabular}{|c|c|}
\hline Rentang & Kategori \\
\hline $1,00-1,99$ & Tidak valid \\
\hline $2,00-2,99$ & Kurang valid \\
\hline $3,00-3,49$ & Valid \\
\hline $3,50-4,00$ & Sangat valid \\
\hline \multicolumn{2}{|c|}{ Sumber : (Madona \& Nora, 2016) } \\
\hline
\end{tabular}

\section{HASIL DAN PEMBAHASAN PENELITIAN}

Proses validasi instrumen penelitian yaitu dengan memberikan instrumen validasi ke validator. Validitas adalah suatu ukuran yang mempresentasikan tingkatan validitas atau kelayakan suatu instrumen. (Khafidin, 2014)Validits tes adalah Seberapa mampu tes itubisa digunakan untuk mengukur sesuatu yang dihendaki untuk diukur. Jadi validitas tes merujuk pada fungsi dari pengukuran tes. Berikut adalah rekapitulasi hasil validasi SAP, Penilaian keterampilan komunikasi dan kolaborasi serta Validasi modul.

Validasi SAP terdiri dari 12 aspek penilaian, berdasarkan hasil validasi didapatkan ada 8 aspek yang memperoleh skor 4 yaitu 1) Capaian pembelajaran mata kuliah memuat aspek sikap, pengetahuan dan keterampilan, 2) Perumusan tujuan /indikator mendukung capaian pembelajaran, 3) Bahan kajian terkait 
408 Validitas Instrument Penerapan Model Quantum Teaching Tipe Tandur terhadap Keterampilan Komunikasi dan Kolaborasi Mahasiswa - Dini Maielfi

DOI: https://doi.org/10.31004/edukatif.v3i2.316

dengan kemampuan yang akan dicapai, 4) Kesesuaian pemilihan model pembelajaran dengan capaian pembelajaran, 5) Kesesuaian sumber belajar /media dengan materi pembelajaran, 6) Kesesuaian pengalaman belajar dengan CPL, 7) Butir-butir penilaian sesuai dengan indikator, 8) Kelengkapan kegiatan (Pendahaluan, inti, dan penuntup). Dan aspek yang memperoleh skor 3 yaitu ada 4 aspek yaitu 1) Kemampuan akhir yang direncanakan pada tiap tahap pembelajaran untuk memenuhi capaian pembelajaran lulusan, 2) Kesesuaian perencanaan waktu dengan materi pembelajaran, 3) Rumusan kalimat komunikatif dan tidak bermakna ganda, 4) Kesesuaian kegiatan dengan model/pendekatan pembelajaran. Berdasarkan 12 aspek penilaian memperoleh jumlah skor 44, rara-rata 3,67 dengan kriteria sangat valid.

Hasil validasi modul terdiri dari 13 aspek penilaian, berdasarkan hasil validasi didapatkan ada 9 aspek yang memperoleh skor 4 yaitu 1) Modul mendorong untuk berkolaborasi atau bekerjasama, 2) Modul menyebabkan belajar tidak membosankan, 3) Modul mendorong untuk saling berkomunikasi, 4) Materi yang disajikan sesuai dengan capaian pembelajaran, 5) penyajian materi dalam modul mendorong untuk berkomuniksi dengan teman lain, 6) modul memuat tes evaluasi yang menguji pemahaman tentang alam semesta, 7) Tidak menggunakan kata/ungkapan yang menimbulkan salah pengertian, 8) bahasa yang digunakan sederhana dan mudah dipahami, 9) bahasa yang digunakan jelas. Dan aspek yang memperoleh skor 3 yaitu ada 4 aspek yaitu 1) Tampilan modul menarik sehingga mendorong untuk belajar, 2) penyajian materi dalam modul mendorong untuk berkolaborasi dengan teman lain, 3) kalimat dalam paragraf yang digunakan dalam modul mudah dipahami, 4) huruf yang digunakan sederhana dan mudah dibaca, Berdasarkan 12 aspek penilaian memperoleh jumlah skor 48,rara-rata 3,69 dengan kriteria sangat valid.

Hasil validasi Penilaian Keterampilan Komunikasi dan Kolaborasi terdiri dari 9 aspek penilaian, berdasarkan hasil validasi didapatkan ada 6 aspek yang memperoleh skor 4 yaitu 1)Lembar penilaian memuat petunjuk yang jelas dan mudah dipahami, 2) Kesesuaian antara Jenis Keterampilan yang dinilai dengan indicator penilaiannya, 3) Kalimat yang digunakan sederhana, jelas dan mudah dipahami, 4) Tidak menggunakan kata/ungkapan yang menimbulkan penafsiran ganda, 5) Kesesuaian antara indicator penilaian keterampilan dengan aspek yang diukur, 6) Kesesuaian antara Rubrik dengan lembar penilaian keterampilan. Dan aspek yang memperoleh skor 3 yaitu ada 3 aspek yaitu 1) Lembar penilaian keterampilan memuat keterangan yang jelas, 2) Kalimat yang digunakan sesuai dengan kaidah Bahasa Indonesia yang baik dan benar, 3) Tidak menggunakan kata/ungkapan yang menimbulkan salah pengertian, Berdasarkan 9 aspek penilaian memperoleh jumlah skor 33, rara-rata 3,67 dengan kriteria sangat valid. Hasil validasi dari perangkat atau intrumen penelitian yang digunakan digambarkan pada grafik 1. Berikut.

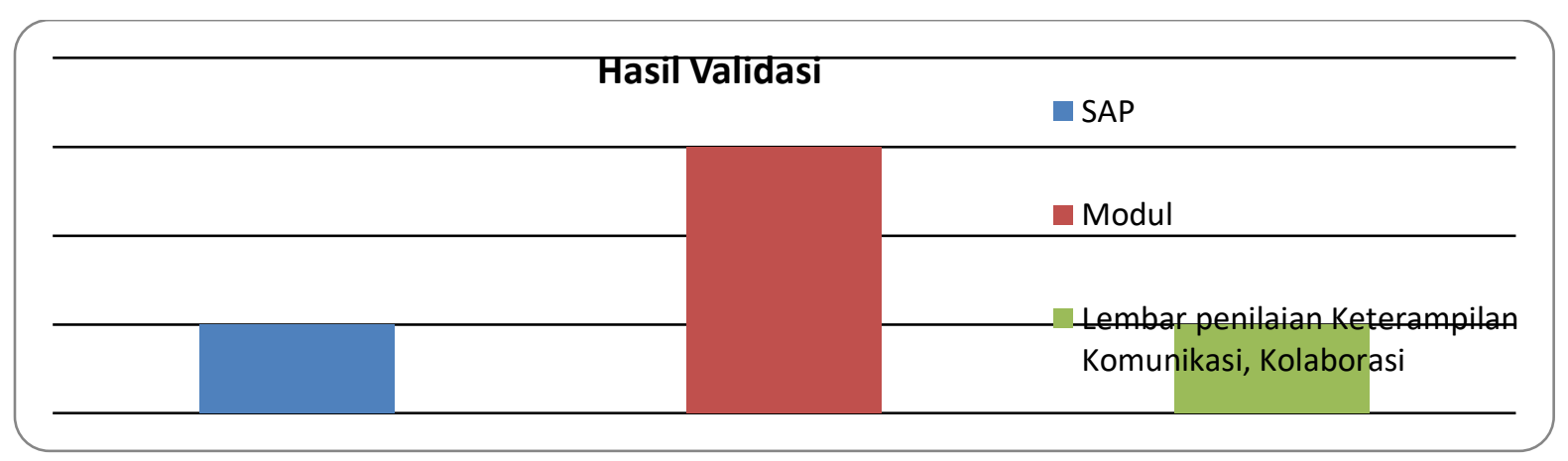

Grafik 1. Hasil Rekapitulasi validasi Instrumen Penelitian

Berdasarkan hasil validitas instrument didapatkan hasil validitas a) satuan acara perkuliahan memperoleh rerata nilai yaitu 3,67 dengan criteria sangat valid, b) modul memperoleh rerata nilai validitas 3,69 dengan criteria sangat valid, c) penilaian keterampilan komunikasi dan kolaborasi memperoleh rerata 
nilai yaitu 3,67 dengan criteria sangat valid, sehingga instrument ini layak dipakai pada suatu riset. (Ihsan, 2015)Jika hasil penilaian termasuk kedalam kriteria sangat tidak valid hingga kurang valid maka dihindari untuk penggunaannya sebagai alat ukur pada riset. Alat ukur ini hendaknya diperbaiki oleh perancang sehingga didapatkan penilaian yang lebih layak dari penilai. Jika setelah diperbaiki alat ukur telah memperoleh nilai cukup valid dan valid maka alat ukur tersebut telah dapat digunakan pada penelitian. Pada alat ukur yang mendapatkan kriteria cukup valid, walaupun sudah dapat dipakai tetapi hendaknya dilakukan revisi lagi kalau mau dipakai untuk penelitian berikutnya.

Hasil penelitian ini sesuai dengan penelitian yang dilakukan oleh peneliti terdahulu 1) (Sudarsana et al., 2020) Hasil penganalisisan validitas isi instrumen aktivitas belajar siswa pada pembelajaran PPKn memperoleh 0,88 dengan kriteria validitas sangat tinggi, ini artinya kualitas yang baik menandakan bahwa instrumen penilaian tersebut layak untuk dipergunakan dalam mengukur aktivitas belajar siswa. 2) Penelitian yang dilakukan (Riyani et al., 2017) Berdasarkan hasil validitas logis, diperoleh rerata validitas tes kemampuan belajar dari tiga orang validator materi yaitu 3,26 jadi dapat disimpulkan validitas tes kemampuan belajar dari pakar materi secara global dinyatakan sangat valid. Uji validitas tiap tes kemampuan belajar memakai korelasi hasil diperoleh dari 25 buah variasites kemampuan belajar, terdapat 20 tes kemampuan belajar yang valid dan 5 tes kemampuan belajar yang non valid. 3) 1) Validitas setelah penilaian uji validator pada Modul Multimedia interaktif berbasis Macromedia Director MX memperoleh nilai 90.35,00\%, sehingga kategori validitas dapat dikategorikan sangat valid dan dapat digunakan pada saat pembelajaran (Sepriana et al., 2019).

Berdasarkan beberapa penelitian terdahulu didapatkan bahwa penelitian yang dilakukan sejalan dengan penelitian terdahulu dan sama-sama didapatkan bahwa pengujian instrument penelitian didapatkan hasil yang valid atau layak digunakan dalam proses pembelajaran. Perbedaan penelitian ini dengan penelitian sebelumnya yaitu instrumen penilaian yang dirancang berbeda dengan instrumen pada beberapa penelitian sebelumnya tersebut, karena belum ada yang mengembangkan dan menguji validitas instrumen penilaian terkait keterampilan komunikasi dan kolaborasi mahasiswa. Jadi kebaruan penelitian ini yaitu dari penelitian ini dihasilkan instrument yang valid untuk digunakan pada penilaian keterampilan komunikasi dan kolaborasi mahasiswa. Keterbatasan penelitian ini yaitu hanya menguji validitas instrumen keterampilan komunikasi dan kolaborasi mahasiswa, dan hendaknya dapat melibatkan 3 orang validator atau lebih sehingga tingkat validitas lebih akurat

\section{KESIMPULAN}

Berdasarkan hasil validitas instrument didapatkan hasil validitas a) satuan acara perkuliahan memperoleh rata-rata nilai yaitu 3,67 dengan criteria sangat valid, b) modul memperoleh rata-rata nilai validitas 3,69 dengan criteria sangat valid, c) penilaian keterampilan komunikasi dan kolaborasi memperoleh rata-rata nilai yaitu 3,67 dengan criteria sangat valid, sehingga instrument ini layak digunakan dalam penelitian. Hal inilah yang membedakan penelitian ini dengan penbelitian terdahulu karena dari penelitian ini dihasilkan instrument SAP, modul dan instrument penilaian keterampilan komunikasi yang valid dan layak digunakan. Implikasi penelitian ini adalah dihasilkan instrumen yang valid dan dapat dipakai saat pembelajaran. Instrumen penilaian ini dirancang berupa lembar observasi dengan beberapa indicator agar memudahkan dalam penilaian sehingga dapat dijadikan solusi untuk mengatasi masalah terkait kualitas penilaian instrumen pembelajaran yang layak dipergunakan dalam menilai keterampilan komunikasi dan kolaborasi mahasiswa. Hal ini sesuai dengan pendapat (Arifin, 2017) Validitas adalah salah satu hal yang utama yang menjadi perhatian oleh peneliti supaya instrumen yang dirancang menjadi baik, sehingga dapat dipergunakan untuk mendapatkan data yang baik juga. 
410 Validitas Instrument Penerapan Model Quantum Teaching Tipe Tandur terhadap Keterampilan Komunikasi dan Kolaborasi Mahasiswa - Dini Maielfi

DOI: https://doi.org/10.31004/edukatif.v3i2.316

\section{UCAPAN TERIMA KASIH}

Ungkapan terimakasih penulis pada semua yang telah berperanserta agar berjalannya riset ini terutama kepada kemristekdikti yang telah memberi bantuan dana agar berjalannya penelitian ini. Kemudian, kepada pimpinan STKIP Adzkia yang telah memberi izin terlaksananya penelitian, rekan anggota penelitian, serta rekan dosen STKIP Adzkia yang telah membantu demi kelancaran penelitian ini.

\section{DAFTAR PUSTAKA}

Arifin, Z. (2017). Kriteria Instrumen Dalam Suatu Penelitian. Jurnal Theorems (the original research of mathematics), 2(1), 28-36.

Hayati, S., \& Lailatussaadah. (2016). Validitas Dan Reliabilitas Instrumen Pengetahuan Pembelajaran Aktif, Kreatif Dan Menyenangkan (Pakem) Menggunakan Model Rasch. Jurnal Ilmiah Didaktika, 16(2), 169. https://doi.org/10.22373/jid.v16i2.593

Ida, I., \& Unsiah, F. (2018). PENGEMBANGAN SATUAN ACARA PERKULIAHAN MATA KULIAH BAHASA INGGRIS UNTUK MAHASISWA FAKULTAS HUKUM UNIVERSITAS BRAWIJAYA MALANG. Jurnal Ilmiah Edukasi \& Sosial, 9(1), 43-48.

Ihsan, H. (2015). Validitas Isi Alat Uukur Penelitian: Konsep Dan Panduan Penilaiannya. PEDAGOGIA Jurnal Ilmu Pendidikan, 13(3), 173. https://doi.org/10.17509/pedagogia.v13i3.6004

Khafidin, Z. (2014). Analisis Validitas dan ReliAbilitas Tes Mata Pelajaran Pendidikan Agama Islam Tingkat SMA A. Edukasia: Jurnal Penelitian Pendidikan Islam, 9(2), 253-266.

Khairani, A. L., \& Ismah, I. (2016). Pengaruh Model Pembelajaran Quantum Teaching Tipe Tandur Diintegrasikan Dengan Kartu Tangram Terhadap Hasil Belajar Matematika Siswa. FIBONACCI: Jurnal Pendidikan Matematika dan Matematika, 2(1), 9. https://doi.org/10.24853/fbc.2.1.9-22

Madona, A. S., \& Nora, Y. (2016). PENGEMBANGAN MODUL IPS BERBASIS MULTIMEDIA INTERAKTIF UNTUK SISWA KELAS IV SEKOLAH DASAR. Jurnal Pelangi, 8(2), 221-228. http://dx.doi.org/10.22202/jp.2016.v8i2.1048

Maielfi, D., \& Wahyuni, S. (2020). The Influence of Jigsaw Type Cooperative Models on Communication Skills of Elementary School Students. Jurnal Penelitian Pendidikan IPA, 6(2), 205-209. https://doi.org/10.29303/jppipa.v6i2.431

Mustika, N., \& Sophia, A. (2019). Edukatif: Jurnal Ilmu Pendidikan. Edukatif: Jurnal Ilmu Pendidikan, 1(3), 107-112. https://edukatif.org/index.php/edukatif/index

Putra, E. A. (2015). Anak Berkesulitan Belajar di Sekolah Dasar Se-Kelurahan Kalumbuk Padang. Jurnal Ilmiah Pendidikan Khusus, 1(3), 71-76. http://103.216.87.80/index.php/jupekhu/article/viewFile/6065/4707

Rahmawati, A. (2019). Analisis Keterampilan Berkolaborasi Siswa SMA Pada Pembelajaran Berbasis Proyek Daur Ulang Minyak Jelantah. Jurnal Pendidikan dan Pembelajaran Kimia, 8(2).

Riyani, R., Maizora, S., \& Hanifah, H. (2017). Uji Validitas Pengembangan Tes Untuk Mengukur Kemampuan Pemahaman Relasional Pada Materi Persamaan Kuadrat Siswa Kelas Viii Smp. Jurnal Penelitian Pembelajaran Matematika Sekolah (JP2MS), 1(1), 60-65. https://doi.org/10.33369/jp2ms.1.1.60-65

Saenab, S., Yunus, S. R., \& Virninda, A. N. (2017). PjBL untuk Pengembangan Keterampilan Mahasiswa: Sebuah Kajian Deskriptif Tentang Peran PjBL dalam Melejitkan Keterampilan Komunikasi dan Kolaborasi Mahasiswa. Seminar Nasional Lembaga Penelitian UNM, 2(1), 45-50.

Sepriana, R., Sefriani, R., Wijaya, I., \& Lestari, P. (2019). Edukatif: Jurnal Ilmu Pendidikan. Edukatif: Jurnal Ilmu Pendidikan, 1(3), 120-126. https://edukatif.org/index.php/edukatif/index 
411 Validitas Instrument Penerapan Model Quantum Teaching Tipe Tandur terhadap Keterampilan Komunikasi dan Kolaborasi Mahasiswa - Dini Maielfi

DOI: https://doi.org/10.31004/edukatif.v3i2.316

Sudarsana, K. N. ., Antara, P. ., \& Dibia, I. . . (2020). Kelayakan Instrumen Penilaian Keaktifan Belajar PPKn. Jurnal Mimbar PGSD Undiksha, 8(2), 150-158.

Utomo, B. (2018). Analisis Validitas Isi Butir Soal sebagai Salah Satu Upaya Peningkatan Kualitas Pembelajaran di Madrasah Berbasis Nilai-Nilai Islam. Jurnal Pendidikan Matematika (Kudus), 1(2), 145-159. https://doi.org/10.21043/jpm.v1i2.4883

Yusup, F. (2018). Uji Validitas dan Reliabilitas Instrumen Penelitian Kuantitatif. Jurnal Tarbiyah: Jurnal Ilmiah Kependidikan, 7(1), 17-23. https://doi.org/10.18592/tarbiyah.v7i1.2100 